\title{
Formality and Informality in Urban Consolidation in the Municipality of Santiago de Cali, Colombia: Revision of Urban Processes of the Last Decades in the Commune
}

\author{
Gustavo Arteaga', Diego Escobar ${ }^{2 *}$ and Carlos A. Moncada ${ }^{3}$ \\ 'Departamento de Arte, Arquitectura y Diseño, Facultad de Humanidades y Ciencias Sociales, Pontificia \\ Universidad Javeriana Cali, Calle 18 \# 118 - 250, Cali, 760031, Colombia; gustavo.arteaga@javerianacali.edu.co \\ 2Departamento de Ingenieria Civil, Facultad de Ingenieria y Arquitectura, Universidad Nacional de Colombia, \\ Sede Manizales. Carrera 27 \# 64-60, Manizales, 170004, Colombia; daescobarga@unal.edu.co \\ ${ }^{3}$ Departamento de Ingenieria Civil y Agricola, Facultad de Ingenieria, Universidad Nacional de Colombia - Sede \\ Bogota, Ciudad Universitaria edificio 214 Oficina 417, Bogota, 111321, Colombia; camoncada@unal.edu.co
}

\begin{abstract}
Objectives: To investigate the urban consolidation processes of the municipality of Santiago de Cali, as well as the transformation patterns of urban surfaces to recognize specific phenomena. Methods/Analysis: Communes as urban surfaces with administrative and territorial elements (therefore, common attributes) are the basis for contrasting specific phenomena that mark the links with the population determinants that transform the territory, which accounts for informality (phenomenon of interest) as a particular way of urbanizing. In this sense, the surface/population relationship produces indicators that, recognized from the present, allow connecting sequentially and temporally with the origins of the process, understanding it as a "cause and effect" relationship that can be structured and systematized in matrices of data that allow to visualize the relationship scenarios. Findings: This vision of formality (on the process of urbanization) has not been characteristic, since the acceleration of many of the determinants that generate it as population growth or economic cycles have distorted how it is seen, while other phenomena have occurred where urbanization outside the perspective of the State became informal, demonstrating the low capacity for intervention. The scenarios of public policies that sought to ensure those minimum urban conditions were blurred with the increase of that informality, becoming one of the issues that the State must face; and in the case of the municipality of Santiago de Cali, there are particularities that have manifested this informality in scales that allow understanding and studying the different aspects that produce it and, at the same time, to characterize it. Application/Improvement: The development of the present investigation allowed observing particular conditions in the design of planning instruments that start from the recognition of this informality as another form of city construction and that complement the study of this type of relations in the territory.
\end{abstract}

Keyword: Cali, Informality, Urban Consolidation, Urbanity

\section{Introduccion}

In the last decades, different urban processes in the municipality of Santiago de Cali (Colombia) have taken place due to the magnitude of several issues that have arisen, in which questions about the capacity of the State to follow the consolidation close to the vision of formality have surfaced. The responsibilities of the reflection of the minimum conditions and guarantees of habitability in the territory correspond to the State because it is in charge of defining the framework from which these can relate to the issue of urbanization, the baseline for understanding

*Author for correspondence 
public services, transportation, equipment, among others, as a fundamental parameter of formality. Since its foundation during the colonizing period of the $16^{\text {th }}$ century, the municipality of Santiago de Cali was characterized by being a crossroads in proximity to the port of Buenaventura, which quickly associated the city to be a type of dry port in the face of difficult weather conditions on the Pacific coast $\frac{1}{2}$, which resulted in a model of urban development based on specific demands that derive from this function, where also illegal transit such as contraband ${ }^{2}$ played a determining role, which remained until the $19^{\text {th }}$ century. In this sense, Figure 1 shows the importance of the ports on the western Pacific coast, since the difficult conditions of connection with the ports of the north of the country (by the rugged tropical mountain systems without consolidated routes) forced to transport the resources extracted by the same peaceful region, which meant the notorious growth of nearby cities such as Cali, Cartago and Popayan 1 .

Under this condition, the consolidation of the city can not be separated from the economic routines ${ }^{3}$, which were characterized by being cyclical and changing, which produce random phenomena that transformed the territory in particular ways, and that in many opportunities escape the way in which the urban processes in the country were observed, since by the temporalities of the phenomena or their specific characteristics, they are not associated to what happened in a typical way in the rest of the territory. In this sense, a part of the phenomena of the urban growth in the municipality that can be related as consequences of economic activities ${ }^{4}$ is not linked to the contexts of study. This means that

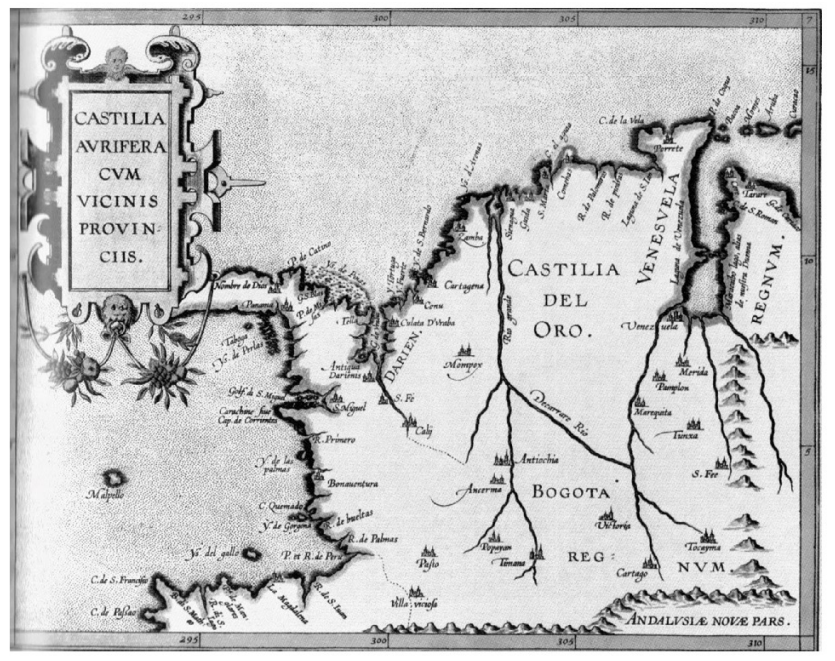

Figure 1. Castilla Aurifera cum vicinis provincias. Mapof Castilla de Oro, 1600. the logic associated with high cycles of economic production that induce accelerated settlement processes, or those that cause expulsion at times of crisis in the productive sectors, are not seen as a direct factor in the ways of building a habitat, ignoring a determining condition that in a specific sense is related to the construction of the house, since it is understood that the housing unit is the basic fact of the population at the moment of migrating or occupying new surfaces.

This basic need in terms of urbanization ends up being the way in which large areas of the city are made from that condition of marked informality and from which one could recognize patterns of how the cultural determinants of the arriving groups materialize, at the moment to transform the territory, to inhabit it and to generate the conditions to survive, far from the accompaniment of the formal condition or what could be associated with it. At this point, the relationship between the economic cyclical factors and the transformation of the surfaces can be studied from the characteristics of the houses, in terms of their general attributes, the location and the moments in which the human settlements begin. Observing retrospectively offers guidelines to understand how the informal phenomena that are manifested today with magnitude as Siloe or Aguablanca ${ }^{4,5}$ can be seen with a perspective that seeks to deepen the social aspects that generated the processes, connecting them to a specific context that responds to a "cause and effect" relationship, establishing an input to see the formal-informal relationship in the production of surfaces in the case of the municipality of Santiago de Cali.

\section{Generalities}

As it was referenced, in the municipality of Santiago de Cali, economic phenomena have been determinants in many of the processes of urban transformation as in other cities of the region ${ }^{6}$, since they are the agents that motivate demographic routines of various natures and that in many cases have only been seen from qualitative conditions, to determine population growth or answer questions from the conjunctural scenarios generated, for example by changes in economic models ${ }^{7}$, where few attributes have been added that account for the characteristics of the groups who have produced the phenomena of transformation of the surfaces of the municipality ${ }^{8}$, thus ignoring widely documented historical facts. In this sense, it is certain that the urban surface was and is a 


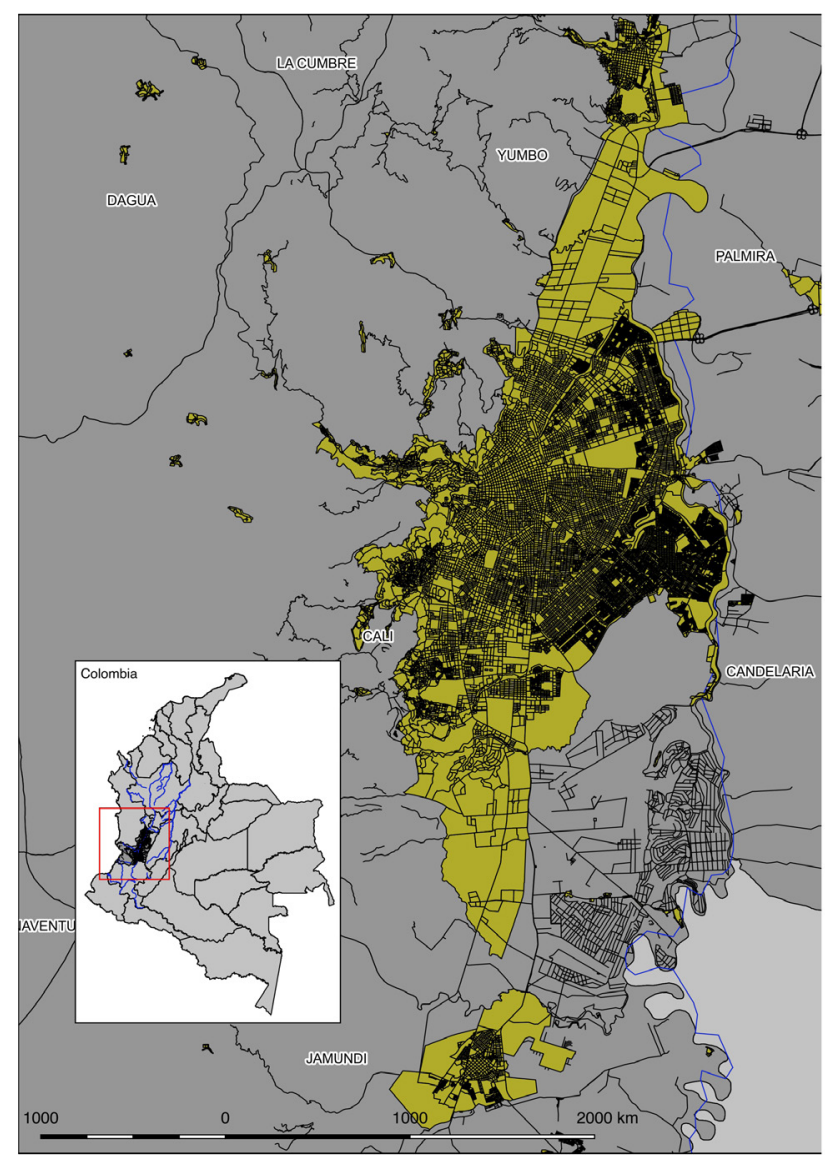

Figure 2. Map of the current urban condition of the municipality of Santiago de Cali.

meeting point of diverse cultural conditions, which have been found for centuries and have urbanized the territory in special ways.

Since the arrival of Afro groups during the $16^{\text {th }}$ century, the Antioquia colonization after the $18^{\text {th }}$ century ${ }^{9}$ and until the arrival of indigenous communities for various reasons such as natural disasters or displacement due to the armed conflict in the country after the second half of $19^{\text {th }}$ century ${ }^{10}$ the phenomena found in the city support are diverse and complex, but the transformations that produced and that leave features, patterns or physical characteristics that can be observed are not fully characterized from the point of view of an input to study the transformations. Under this possibility, the conditions of the houses, the ways of grouping to conform the urban facts, or the constructive materials, among others, are elements to be observed, since the places where they are given, the quantity, the moments, or itself as a constructive, give a direct account of how the arrival of different population groups. The specific condi- tions that produce their facts also give details that make it possible to understand how to urbanize, in a way that was far from the logic of action of the State that therefore responds to informality.

This scenario allows understanding that the current state of the municipality of Santiago de Cali (see Figure 2) is a result of the different ways in which the city was made and, therefore, it is possible to understand from those forms the specific processes that were the result. The housing as basic infrastructure is a first element to be seen in its relationship with administrative determinants (such as communes or neighborhoods) in terms of their grouping, relationship existent among different types of surfaces and uses or subsequently constructive characteristics of the sets.

\section{Materials and Methods, Urban Structural Variables of the Municipality}

As a methodology, it is proposed to analyze the information that describes the characteristics of the housing infrastructure placed in the context of the migrations that occurred at different times, which are related to economic cycles. In this way, it is possible to understand the logic that induces the processes from the identifiable social groups that produce a city with morphological and typological particularities, which can be observed when demarcating the territories, and unfold the generic condition used until nowadays to see characteristics that are related to the informality as processes of generation of urban surfaces in Colombia. In this perspective, the current form of the municipality (see Figure 2) is understood as a sum of phenomena of different natures that are induced by special events, which, due to the observable characteristics of the variety of human groups present in the territory of Cali, can be segregated in order to understand the logics from which the different sectors of city that these groups inhabit, or in a more complex sense, to see the different layers of city that each population group produces and that are superimposed to conform the current urban condition.

The first data of interest is to observe the urban expansion compared from the current situation (which defines the urban perimeter), to the historical condition close to the decade of the $90 \mathrm{~s}$, decade in which different economic crises can be related to the scenario of the urban 
Table 1. Relationship of the urban surface according to hectares and population of the municipality Santiago de Cali

\begin{tabular}{|l|c|c|c|c|c|c|c|c|c|c|}
\hline \multicolumn{1}{|c|}{ Year } & 1987 & 1989 & 1990 & 1991 & 1997 & 2000 & 2001 & 2002 & 2013 & 2016 \\
\hline $\begin{array}{l}\text { Surface area } \\
(\mathbf{H a})\end{array}$ & 8,695 & 8,695 & 8,695 & 11,274 & 11,274 & 12,097 & 12,097 & 12,097 & 12,097 & 12,097 \\
\hline $\begin{array}{l}\text { Population } \\
(\mathbf{0 0 0})\end{array}$ & 1,492 & 1,589 & 1,635 & 1,679 & 1,886 & 1,962 & 1,985 & 2,009 & 2,283 & 2,358 \\
\hline
\end{tabular}

Table 2. Consolidated population information of the municipality of Santiago de Cali from 1912 to 2016, treated statistically to form study scenarios and see the magnitude of the demographic particularities

\begin{tabular}{|c|c|c|c|c|c|}
\hline Year & Population & Scenarios & Sub-scenario & Difference & \\
\hline 1912 & 27,747 & \multirow{7}{*}{1} & \multirow{3}{*}{$1 \mathrm{~A}$} & 27,747 & \multirow{3}{*}{241,357} \\
\hline 1938 & 88,366 & & & 60,619 & \\
\hline 1951 & 241,357 & & & 152,991 & \\
\hline 1964 & 618,215 & & \multirow{2}{*}{$1 \mathrm{~B}$} & 376,858 & \multirow{2}{*}{649,830} \\
\hline 1973 & 891,187 & & & 272,972 & \\
\hline 1985 & $1,323,944$ & & $1 \mathrm{C}$ & 432,757 & 432,757 \\
\hline 1992 & $1,714,363$ & & $1 \mathrm{D}$ & 390,419 & 390,419 \\
\hline 1997 & $1,922,633$ & \multirow{7}{*}{2} & $2 \mathrm{~A}$ & 208,270 & 208,270 \\
\hline 2000 & $2,071,227$ & & \multirow{3}{*}{$2 \mathrm{~B}$} & 148,594 & \multirow{3}{*}{197,210} \\
\hline 2002 & $2,045,944$ & & & $-25,283$ & \\
\hline 2005 & $2,119,843$ & & & 73,899 & \\
\hline 2012 & $2,294,653$ & & \multirow{3}{*}{$2 \mathrm{C}$} & 174,810 & \multirow{3}{*}{238,459} \\
\hline 2014 & $2,344,734$ & & & 50,081 & \\
\hline 2016 & $2,358,302$ & & & 13,568 & \\
\hline
\end{tabular}

Table 3. Number of urban dwellings in the municipality of Santiago de Cali from 1987 to 2016 according to information from the municipal administration

\begin{tabular}{|c|c|c|c|c|c|c|c|c|}
\hline Description & 1987 & 1989 & 1990 & 1999 & 2000 & 2010 & 2015 & 2016 \\
\hline Houses & 297,743 & 321,015 & 333,303 & 429,427 & 440,642 & 563,669 & 624,000 & 636,158 \\
\hline
\end{tabular}

Table 4. Relation of information of numbers of houses and population by communes between 1987 and 2013

\begin{tabular}{|c|c|c|c|c|c|c|c|c|c|}
\hline Year & 1987 & 1989 & 1990 & 1999 & 2000 & 2010 & 2011 & 2012 & 2013 \\
\hline Houses & 297,743 & 321,015 & 333,303 & 429,427 & 440,642 & 563,669 & 575,359 & 587,520 & 599,681 \\
\hline Difference & & 23,272 & 12,288 & 96,124 & 11,215 & 123,027 & 11,690 & 12,161 & 12,161 \\
\hline Percentage & & $8 \%$ & $4 \%$ & $24 \%$ & $3 \%$ & $29 \%$ & $3 \%$ & $2 \%$ & $2 \%$ \\
\hline Census year & \multicolumn{2}{|c|}{1985} & 1992 & \multicolumn{2}{|c|}{2000} & \multicolumn{3}{|c|}{2012} & 2014 \\
\hline Population (000) & \multicolumn{2}{|c|}{1,324} & 1,715 & \multicolumn{2}{|c|}{1,923} & \multicolumn{3}{|c|}{2,295} & 2,345 \\
\hline Difference & & & 390,419 & \multicolumn{2}{|c|}{208,270} & \multicolumn{3}{|c|}{372,020} & 50,081 \\
\hline Percentage & & & $29 \%$ & \multicolumn{2}{|c|}{$12 \%$} & \multicolumn{3}{|c|}{$19 \%$} & $2 \%$ \\
\hline
\end{tabular}


development of the Municipality, and of this form to conform a state of contrast of easily tieable aspects, in sense of recent phenomena in temporary terms of the urban development (five decades).

In order to observe this process, Table 1 is generated, where the area in hectares of the municipality and the population are related from 1987 to 2016, according to information deposited in the National Statistical Administrative Department (DANE) ${ }^{\underline{11}}$ which is collected by the municipalities and is structured from the platform "in figures"

In Table 1, it is interesting to observe how between 1990 and 1991 there was an increase in the surface area of the municipality, which can be understood from the entry into force of the Land Management Plans (POT), established by law $388^{\frac{13}{3}}$, where defining the urban perimeter was one of the first demands. At this point, a relationship is not identified when it is contrasted with population growth, since the area increases by about $30 \%$ and the population does not increase in the same way, which can be understood as the enabling of a soil to allow an expansion in next decades. Likewise, in Table 1 it is observed that, in the year 2000, more surfaces were added to the urban perimeter, accumulating close to $40 \%$, which ends up moving away from the condition of population growth, marking an urban routine of interest.

It is important to highlight the population's behavior in historical perspective Table 2 consolidates the data of interest. When applying a grouping criterion to the total population data from 1912 to 2016, the statistical analysis places in 1992 the moment where the number of population breaks growth in two moments (or scenarios), and close to one million seven hundred thousand inhabitants from the demographic change in the municipality within the spectrum that forms the sample.

In the research, so-called sub-scenarios have been named. It is interesting to name 1B (between 1964 and 1973), since it is the historical moment in which the city presents a greater population growth, by making the operation of difference between the number of inhabitants according to the census with respect to the previous period, which in turn is defined by the sum of the years generated by the sub-scenario that was statistically established in Table 2. Other sub-scenarios of interest due to the difference in magnitude are 1C and 1D (between 1985 and 1992), which confirms, from a demographic scenario, the time range previously proposed according to perspectives that have to do with economic and productive conditions. On the other hand, the longest period with 39 years is between 1912 and 1951 (sub-scenario 1A), followed by $1 \mathrm{C}$ with 12 years and $1 \mathrm{~B}$ with 9 years. Therefore, the different demographic phenomena take the longest period of time in scenario 1 , which lasts 90 years, compared to scenario 2, which only lasts 19 years. At this moment, the city doubles its population, or if the population of 1951 is taken as a reference, it is possible to note how in 2016 the population multiplied by approximately nine, which is not a minor fact if one takes into account that there are only six decades that take place, which undoubtedly appears as a fact that, by magnitude, is translated into forms as the great transformations of the territory of the municipality occurred. The times with the logic that induces them are close to these dates, which without a doubt is a condition of great value to understand the processes of consolidation, development and expansion of the urban area of the municipality.

With this perspective, it is important to start observing how the magnitude of the demographic events affects the number of dwellings, according to Table 2. Table 3 shows the amount of urban housing from 1987 to 2016, which allows contrasting with four of the sub-scenarios generated in Table 2. In the first measurement in 2010 and 1999, respectively, there is an increase in magnitude outside the temporary condition of the table, which represent respectively $29 \%$ more units and then an additional 25\%. During the previous two years, the accumulated needs during the previous periods that induce the increase translate into the fact that between 2000 and 2010, 123,027 units were built (or entered into the housing inventory), while between 1990 and 1999, 96,124 housing units were entered according to the information of the administration.

At this point, the possibility of linking the information from the population census of Table 2 is opened, in order to consolidate the limits of the phenomena that up to now have been evident. Table 4 is the result of this and makes it possible to understand, with another perspective, the quantitative phenomena that have been shown. As indicated, and according to the number of dwellings registered in Table 3 , around 1999, the increase in units breaks the condition of the previous years, which, considering the information of the population, is similar to what was observed in 1992, when the population had an increase close to $30 \%$, possibly explaining the need or demand for housing units. Then, in the years 2000 and 2012 another strong period of population growth is accumulated which is also related to what happened in terms of housing in 2010. In terms of magnitude, it is striking to observe how the percentages of increase in the number of dwellings population keep a certain type of proportionality. 
Under this scenario, it is methodologically established that demographic phenomena are closely related to the way housing units are built, but not to the way in which new urban land is enabled. It is at this point that the power to visualize the location of communes will give context to the scenarios delimited until now. For this, observing the quantity of houses in each commune within the temporary ranges seen is an input that allows deepening the investigation. In this way, Figure 3 consolidates the information by communes but once again the restriction in terms of maintaining the nature of the information to allow the contrast makes it only available since 2005 . Nevertheless, because of the limited conditions of interest, it is possible to use the data to understand the ways and then, using the same methodology, to complement other scenarios of greater antiquity. It is possible to understand that the communes do not present proportional amounts of housing. These differences allow to see how heterogeneity accounts for diverse urban processes where consolidation, development and expansion are basic characteristics, and in turn, observe the way in which in each commune there has been an increase of units also forms another specific scenario where commune 6 and 17 define a marked activity within the period of study, followed by 2, 5, 14, 15 and 19 and, as a particular case, the commune 22 for the small amount of units within the consolidated data universe.

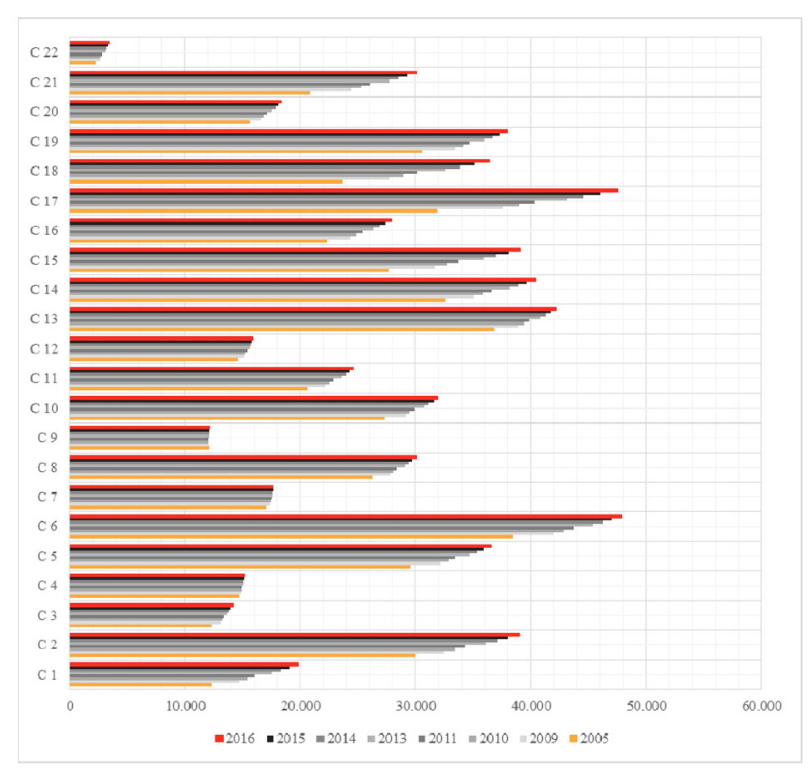

Figure 3. Amount of housing by commune and its variation between 2005 and 2016 .

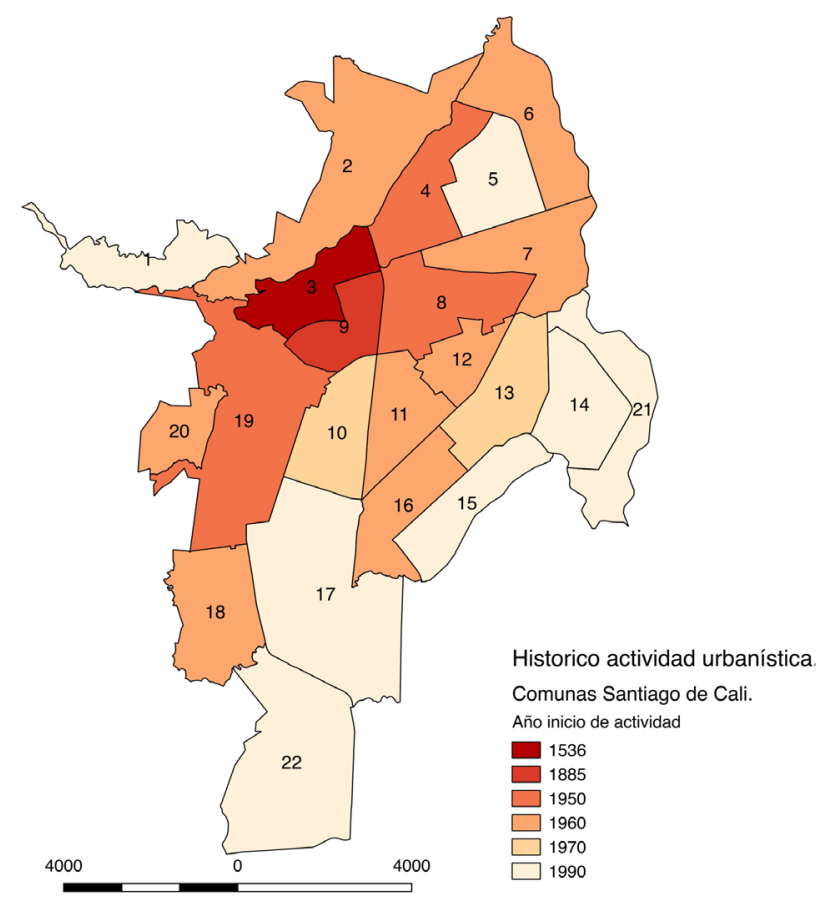

Figure 4. Map by communes where the approximate year during which the urbanization processes begin.

The magnitude of the phenomena studied opens the question as to how be the communes where these processes have been presented, since the number of households shows that this heterogeneous reality is related to the processes that have consolidated urban events under the perspective studied and consolidated in Table 4. Nevertheless, the historical perspective of the processes of consolidation of the communes is necessary to contrast the already referenced heterogeneity of the 22 communes of the municipality, while accounting for the moments seen in Table 2. Because of the limited information available, details are lost in terms of the long-term historical sense generated by the current state of the urban area of the municipality of Santiago de Cali. Therefore, in the plane of Figure 4, using the color as a code, the antiquity of the town planning processes at the commune level is shown since the same founding event (year 1536) which is located on the surface that today forms the commune three, up to the twenty-second commune that, in temporal terms, represents the most current processes incorporated into the urban perimeter of the city.

With the condition that exposes the plan, it supports the aforementioned with respect to the decades in which the greatest processes of urban transformation 
took place, the temporary mark of greater magnitude being between 1950 and 1970, which coincides with the demographic processes indicated in Table 2, and have a correlation with respect to the number of houses inventoried.

\section{Results and Discussion}

Between 1938 and 1951, the municipality tripled its population, which was located in what are now communes 4 , 8 and 19, following the pattern of expansion initiated in commune 9, where the first neighborhoods of labor were located as El Obrero (founded in 1919), and a migrant population of the Pacific coast. This information is directly linked to this research, for it regards the process of urban consolidation according to population groups. This temporality shown delimits sectors of the city, which are distant from each other. This means there are different processes that, although they could share the moment of the urbanizing activity, still suggest that the actors that carried out the process were different. This is an input of value to understand the characteristics of the ways in which the municipality was developed. Under this determinant, the socio-economic stratum attribute at present accounts for specific characteristics that have to do with the physical conditions of the neighborhoods according to the dwellings. Thus, associated with the scenarios and sub-scenarios of Table 2, it offers a framework to observe in detail the ways in which the processes occurred and to link it to the human groups that generate them.

The map of Figure 5 is generated with the stratum 1 and 2 neighborhoods located within the current urban perimeter of the municipality of Santiago de Cali, which, associated with what has been referenced up to now, is evidence based on the age of the map in Figure 4. Places where possibly different actors or communities initiated urban and transformation processes that are analyzed in detail can account for the characteristics of processes of informal origin initiated after 1938, but that under the current regulatory condition are associated with greater ease to the data after 1973, where determinants close to the internal conflict as a generator of internal migrations ${ }^{\underline{14}}$ can be linked directly and where recognizing the characteristics of informality as generative patterns of the city are an input to understand different dynamics and challenges of planning nowadays.

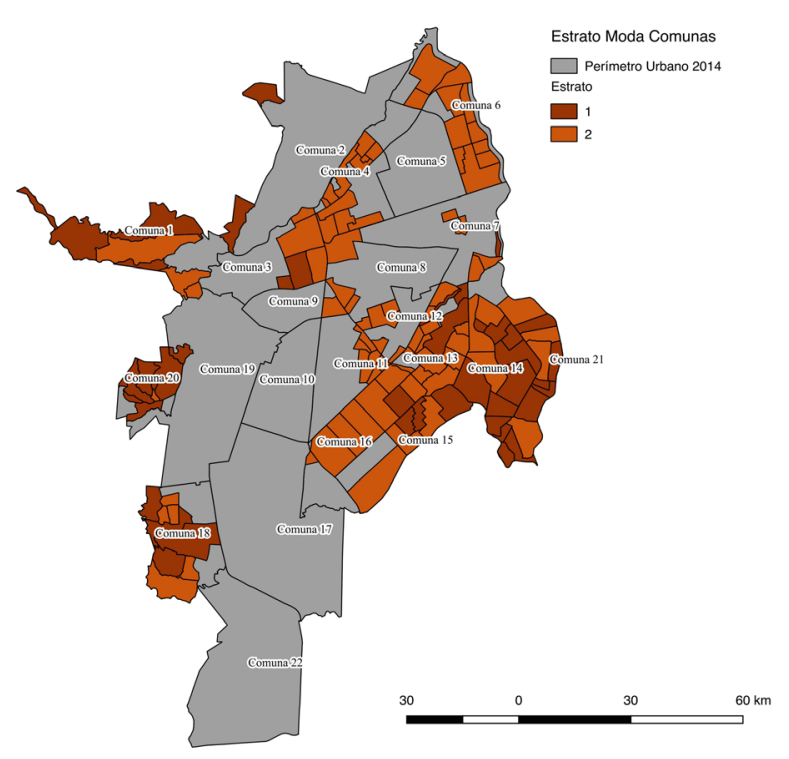

Figure 5. Neighborhoods by socio-economic stratum 1 and 2 by communes of the municipality of Santiago de Cali.

With the information treated, it is possible to assert that a large proportion of the neighborhoods that make up stratum 1 and 2 in the municipality of Santiago de Cali accounts for informal processes that were incorporated into the urban perimeter after 1991. These processes respond to different times that are associated with economic and productive routines that come from the late $19^{\text {th }}$ century, when the population of the Pacific coast began to arrive in the city, attracted by the labor supply and where the railroad and the port of Buenaventura were a determining factor. At that time, the surfaces that were located in what is now known as the 9th commune, were the place where the first worker settlements can be identified and which were expanded following the railroads. After 1951, the process accelerated and the transformation of surfaces takes special magnitude. From this moment urbanization processes with characteristics close to what is currently understood as informality can be recognized and can be seen today under the attribute of the socio-economic stratum that the neighborhoods of the city conserve. Figure 3 clearly shows the sectors where these phenomena must have originated, where Siloé and the Aguablanca district can be recognized, supporting the proposed idea. Under this perspective, this plan becomes an input to differentiate in a preliminary way six major phenomena which are motivated by different population groups and in parallel to what can be called formal or 
promoted from the logic of the State. In this sense and according to what was structured with the information, it is possible to propose that before the year 2000, about $30 \%$ of the surface of the municipality was of informal origin and an equal or a little greater percentage of the population was in turn who inhabited the city in this way, which in representative terms evidences the little capacity of the State to accompany the processes of urban development during this time which undoubtedly led during the 90s to propose profound reforms to the political system which culminates with the new Constitution in $1991^{15}$ and new territorial zoning frameworks ${ }^{\underline{13}}$ complementary to existing ones ${ }^{\frac{16}{6}}$.

\section{Conclusions}

Within the urban processes given in the municipality of Santiago de Cali, it is important to understand that demographic behavior assumes routines that directly affect the ways of building a city and in this sense informality is a fact of great magnitude as analyzed in this investigation. Observe that, after 1950, the informal production of the city could generate more than $40 \%$ of the current city. They represent a tension between two ways of doing with the same force, with what in practical terms can be understood as two cities (the formal and informal) that overlap in a territory and are physical characteristics such as topography or hydrography, those in charge of defining limits. Under this idea of two cities built with different logics that overlap in a territory, it is clear that the role of the State happens to act only from the instruments that allow it to diagnose and see the city that responds to its logic, i.e., the formal, for therefore the other city took magnitude before the inability of State to observe, understand and diagnose that other reality, clearly surpassing the technical capacities and the instruments with which a large part of the municipality's history has been ignored as an input to establish or least theorizing about the proper urbanism generated by the routines that transformed the territory.

\section{References}

1. Zambrano F, Olivier B. Ciudad Y Territorio Elproceso de poblamiento en Colombia. Academia De Historia De Bogota Institut, O Frances De Estudios Andinos. 1993; p. 1-280. https://doi.org/10.4000/books.ifea.2083.
2. Parsons J. El poblamiento de Uraba durante la epoca colonial. El escenario físico. Revista de la Universidad Nacional (1944 - 1992). 1967; 13:1-22.

3. Urrea F. Transformaciones sociodemograficas y grupos socio-raciales en Cali a lo largo del siglo XX y comienzos del siglo XXI. Programa Editorial Facultad de Humanidades, Universidad del Valle. 2011; p. 1-48.

4. Vásquez E. Historia del desarrollo económico y urbano en Cali. Boletín Socieconómico, 1990; 20: 28.

5. Maria A, Florez V. El Proceso De Urbanizacion De La Comuna 22: Estudio Sobre Sus Repercusiones En El Barrio Valle Del Lili. Universidad ICESI. 2013; p. 1-53.

6. Jordan R, Simioni D. Ciudades intermedias de America Latina y el Caribe: Propuestas para la gestion urbana. CEPAL. 1998; p. 1-450. PMid:9466791

7. Baeza D Tugurios. migracion y objetivos de desarrollodel Milenio. Serie Poblacion Y Desarrollo, Centro Latinoamericano y Caribe-o de Demografía (CELADE) Division de Poblacion de la CEPAL. 2007; p. 1-78.

8. Torres C. Ciudad informal colombiana: Barrios construidos por la gente. Universidad Nacional de Colombia, Bogota. 2009; p. 1-320.

9. Londo-o J. El modelo de la colonizacion antioque-a. Un balance historiografico. Fronteras de La Historia. Instituto Colombiano de Antropologia E Historia. 2002; 7:187-226.

10. UNHCR-ACNUR. Agencia de la ONU para los Refugiados ANUR. Comunidades indigenas en Colombia. 2011; p. 1-35.

11. Departamento Administrativo de planeacion Municipal. Cali en Cifras. Available from: http://planeacion.cali.gov. co/Publicaciones/Cali_en_Cifras/Caliencifras2013.pdf. Date accessed: 09/02/2018.

12. Alcaldia de Santiago de Cali. Cali en Cifras. 2018. Available from: http://www.cali.gov.co/publicaciones/107143/cali_ en_cifras_planeacion/. Date accessed: 28/04/ 2018.

13. Congreso de Colombia. Ley 388 de 1997. Available from: http://www.alcaldiabogota.gov.co/sisjur/normas/Norma1. jsp?i=339. Date accessed: 18/07/1997.

14. Granados J. Las migraciones internas y su relacion con el desarrollo en colombia. Una Aproximacion desde algunos estudios no clasificados como migracion interna de los ultimos 30 a-os. Pontificia Universidad Javeriana. 2010; p. 1-133.

15. Congreso de Colombia. Constitucion Politica de Colombia. 1991. Available from: https://es.wikipedia.org/ wiki/Constituci\%C3\%B3n_de_Colombia_de_1991. Date accessed: 16/07/2018.

16. Summary for Policy makers. Available from: http://doi. org/10.1017/CBO9781107415324.004. Date accessed: 06/2014. https://doi.org/10.1017/CBO9781107415324.004. 